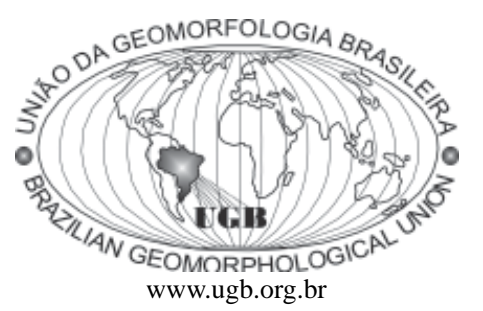

\title{
COMPARTIMENTAÇÃO MORFOTECTÔNICA E IMPLICAÇÕES DE EVOLUÇÃO DO RELEVO DO HEMIGRÁBEN DO TACUTU NO ESTADO DE RORAIMA
}

José Augusto Vieira Costa

Geólogo - Analista de Infraestrutura - Secretaria de Geologia, Mineração e Transformação Mineral - SGM/MME Esplanada dos Ministérios Bloco “ $U$ ”, $4^{\circ}$ Andar sala 440, Brasília, DF, Tel.: 0xx61 3319-5386 CEP 70.065-900 - e-mail: jose.costa@mme.gov.br

Márcia Teixeira Falcão

Professora coordenadora do curso de Saneamento Ambiental do Instituto Federal de Educação, Ciência e Tecnologia de Roraima, IFRR - e-mail: marciatfalcao@yahoo.com.br

\begin{abstract}
Resumo
Este estudo descreve de forma sucinta a análise morfotectônica do hemigráben do Tacutu em Roraima. Para realização dessa pesquisa foram levados em consideração os dados já existentes na literatura referente a área abordada, além de diversas pesquisas de campo para entendimento do seu processo evolutivo, utilizando técnicas de mapeamento geomorfológico e de geoprocessamento tendo como repositório um banco de dados do SIG ArcGis 9.3. O processo evolutivo dessa bacia sedimentar esteve condicionado a sucessivos eventos climáticos e neotectônicos ocorridos na região durante o final do Terciário e Quaternário, que podem ser evidenciados pela presença de linhas de pedras, campos de paleodunas e ainda o registro de falhas normais e transcorrentes que produzem inúmeras anomalias de drenagem. Essas características se constituem em evidências da evolução do relevo facilitada pela atividade neotectônica na região.
\end{abstract}

Palavras-chave: hemigráben do Tacutu, controle neotectônico, evolução de relevo

\begin{abstract}
This study describes succinctly the morphotectonic analysis of thehemigraben of Tacutuin Roraima. Forthis survey were takeninto account the existing data about the study are a andseveral researchesin the field tounderstandits evolutionary process, using techniques of geomorphological mapping and geographic information system having as repository adatabase of GISArcGIS9.3. The evolution process of sedimentary basinhas beenconditioned by successive climatic and neotectonic events occurring in the region during the Late Tertiary and Quaternary, which can be evidenced by the presence of stone lines, paleodunes fields and even presence of transcurrent and normal faults that produce numerous drainage anomalies. These characteristics are evidence of the evolution of relief facilitated by neotectonic activity in the region.
\end{abstract}

Keywords: Tacutu hemigraben, neotectonic control, evolution of the relief. 


\section{Introdução}

Este artigo aborda a evolução da paisagem no hemigráben do Tacutu em Roraima, principalmente com base no contexto morfoestrutural, a bacia sedimentar do Tacutu, que compreende uma geometria em hemigráben encaixado no Escudo das Guianas, que se alonga na direção nordeste - sudoeste, com cerca de $300 \mathrm{~km}$ de comprimento, variando entre 30 a 50km de largura, estendendo-se da República da Guiana, à capital do Estado de Roraima, Boa Vista.

O hemigráben foi implantado em uma zona de reativação do Cinturão Guiana Central. A dinâmica e evolução das formas de relevo e dos aspectos morfoestruturais estão condicionadas ao resultado de sucessivos estágios de reativação, os quais têm como condicionantes os processos tectônicos e os agentes externos que variam ao longo do tempo, e que foram impressos como diferentes feições internas da bacia do Tacutu, tornando-se, assim, uma área de relevo atípico em território roraimense.

As morfoestruturas denunciam que o "rift" esteve sujeito a vários estágios de basculamentos, que gerou blocos rotacionados, resultando em regiões aplainadas, rebaixadas e áreas soerguidas como a serra do Tucano e sequências de morros alinhados.

As inúmeras anomalias de drenagens presentes, tais como drenagem em cotovelo, em ângulos retos, paleocanais e capturas demonstram indicar movimentações neotectônicas.

A modelagem digital do terreno conjuntamente com o estudo das estruturas macro e mesoscópicas, e registros de movimentação da sedimentação subrecente, foram de fundamental importância para o entendimento da evolução da paisagem relacionada ao hemigráben.

\section{Breve Histórico}

SHAEFER; VALE Jr., 1997 descreveu que ao final do Cretáceo, a Fossa Tacutu estava completamente cheia, com sedimentos, e o Oceano Atlântico tinha se aberto ao norte e ao leste. As mudanças topográficas resultantes realinharam a drenagem do alto Rio Branco, de forma que ele fluiu rumo norte, para o Rio Berbice e o Mar do Caribe, seguindo a borda da Fossa Tacutu. Este ciclo denudacional resultou no acúmulo de mais de 4.900 metros de sedimentos, levando à formação dos conjuntos Tucano e Tacutu.

Este novo sistema fluvial, chamado de Proto-Berbice tinha suas cabeceiras meridionais em uma antiga cadeia de montanhas, representada, hoje, pelas Serra de Parima, Demini, Apiaú, Mucajaí, Mocidade, Grande, Lua, Anauá e Acaraí, e drenou para o norte até o fim do Terciário, ou início do Holoceno.

Os principais tributários do Proto-Berbice eram os rios Mucajaí, Uraricoera, Surumu, Parimé, Cotingo, Maú e Tacutu O clima global continuou árido no início do Terciário, indo até o fim do Paleoceno, resultando em intensa erosão do que sobrou do Supergrupo Roraima e na sedimentação de espessos depósitos arenosos em ambos os lados do paleo-divisor Proto-Berbice/Amazonas.

Este ciclo de erosão continuou até o Eoceno, resultando em uma extensa superfície erodida, chamada de pediplanície Sul Americana. Esta superfície, na qual as elevações variam entre 800 e 1000 metros, cobriram a maior parte da Bacia do Rio Branco e ainda hoje está amplamente representada nas cadeias de montanhas mais baixas dessa bacia, interceptando várias formações geológicas, incluindo o Supergrupo Roraima, o Grupo Surumu e a Formação Pedra Preta (SHAEFER; VALE Jr., 1997).

Dois ciclos adicionais de denudação, Velhas I e Velhas II, ocorreram durante o Terciário e o Pleistoceno. O Ciclo Velhas I, resultou na erosão de uma grande porção de pediplanícies iniciais e criou uma nova superfície erosional com elevações que variavam de 200 a 500 metros. O Ciclo Velhas II ocorreu durante o Plioceno e Pleistoceno, no qual a maioria dos altiplanos restantes nas partes centrais e meridionais da bacia foi erodido durante este ciclo e uma nova superfície erosiva, geralmente chamada de Pediplanície Rio Branco, foi criada com elevações que variavam de 80 a 200 metros, onde os pedimentos apresentam-se escalonados e mal drenados na sua porção inferior.

A característica sedimentar resultante, denominada Formação Boa Vista, ainda cobre, atualmente, uma grande porção das planícies a nordeste. Os sedimentos terciários depositados ao sul do paleodivisor produziram a Formação Alter do Chão. Estes depósitos estão agora cobertos com sedimentos andinos da Formação Solimões, depositados no Pleistoceno.

O processo de evolução tectônica da bacia do Tacutu ocorreu em dois episódios de movimentação: o primeiro no Mioceno dominou a subsidência na porção centro-norte e soerguimento na porção centro-sul, situação que parece ser comum em estruturas em forma de cunha, geradas por sistemas transcorrentes dotados de movimentação dextral. Durante o plio-plestoceno, a Bacia do Tacutu criou uma nova planície erodida.

\section{Área de estudo}

Aárea estudada localiza-se no setor centro-nordeste do Estado de Roraima, abrangendo os municípios de Bonfim e Boa Vista, entre as coordenadas $3^{\circ}$ a $3^{\circ} 45^{\prime}$ de latitude norte e $59^{\circ} 40^{\prime}$ a $60^{\circ} 33^{\prime}$ longitude oeste, abrangendo as Folhas NA.21-V-A (Bonfim), NA.20-X-D (Boa Vista) e NA.21-V-C (Rio Tacutu) e NA.20-X-B (Maloca Serra da Moça)

Aárea encontra-se inserida numa unidade geotectônica denominada Cinturão Guiana Central (definido por LIMA et al., 1982) A região limita-se ao norte com o município de Normandia, a leste com a República da Guiana, a oeste com os municípios de Boa Vista e Cantá e, ao sul, com o município de Cantá. 


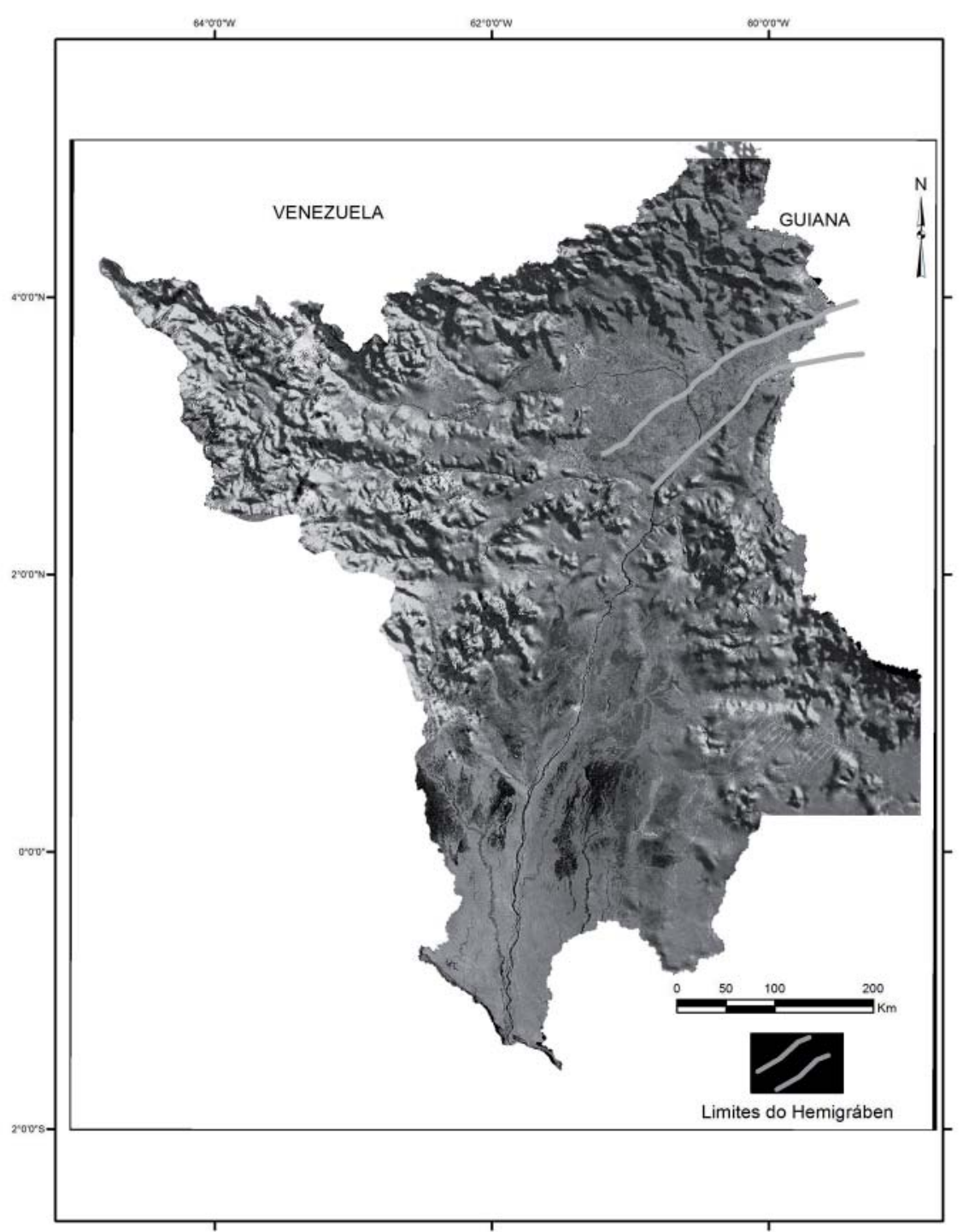

Figura 1 - Mosaico de imagem raster (SRTM) do Estado de Roraima com a localização do Hemigráben do Tacutu.

\section{Metodologia}

A realização desta pesquisa ocorreu em três etapas. No primeiro momento, deu-se prioridade ao entendimento dos estudos anteriores, a exemplo da análise dos mapas geológico-estrutural, dados da sedimentologia, geomorfologia, hidrográficos e cartas estratigráficas. Em um segundo momento, foram georreferenciadas as cartas planialtimétricas e digitalizados mapas preliminares no aplicativo ArcGis 9.3 para suporte aos trabalhos de campo.
No tocante à identificação das feições morfológicas das folhas Boa Vista, Serra da Moça,Tacutu, Bonfim e Normandia, em escalas1:250.000, 1:100.000 e as imagens de satélite LandSat 7 ETM+, cenas 232/58; 231/58; 232/57 (cobertura 2000), permitiram a extração de lineamentos, semelhante à metodologia adotada nos trabalhos de Riccomini e Crosta (1988), que considera a análise de feições lineares do relevo e sua relação com a reconstrução de eventos neotectônicos e o consequente desencadeamento dos processos erosivos e deposicionais. 
Durante a investigação de campo foram identificadas descontinuidades estruturais indicativas de relevos tectônicos (famílias de falhas, fraturas e juntas) e suas relações com o modelamento atual da paisagem. Também foram reconhecidos remanescentes proterozóicos a exemplo dos gnaisses da serra Murupu e mesozoicos como as vulcânicas básicas do morro do Redondo.

Quanto ao registro sedimentar subrecente, observou-se inúmeras ocorrências de linhas de pedra com feições de movimentação fracamente delineadas, entretanto, é bem evidente a formação de pequenos paleovales preenchidos por esse material coluvial, também verificou-se a presença de pequenos campos de matacões lateríticos isolados. Na serra do Tucano foram individualizadas falhas nos estratos sedimentares (siltitos e arenitos), mas de difícil caracterização se inversas ou normais devido ao estado intempérico.

Já na região do igarapé Arraia, em basaltos os afloramentos se dispõem em padrão escalonado com abundantes estrias de falhas primeiramente orientadas subhorizontais superpostas por estrias sub-verticalizadas, sugerindo que falhas transcorrentes foram sobrepostas por falhas normais.

A drenagem regional é caracterizada por duas orientações preferenciais, uma escoando de NE para SW, onde se inclui o hemigráben, outra de oeste para leste sendo que essas desaguam no rio Branco (a exemplo do rio Uraricoera). Uma característica especial é o rio Tacutu que incialmente escoa de sul para norte e posteriormente é capturado pelo hemigráben e passa a escoar de NE para SW.

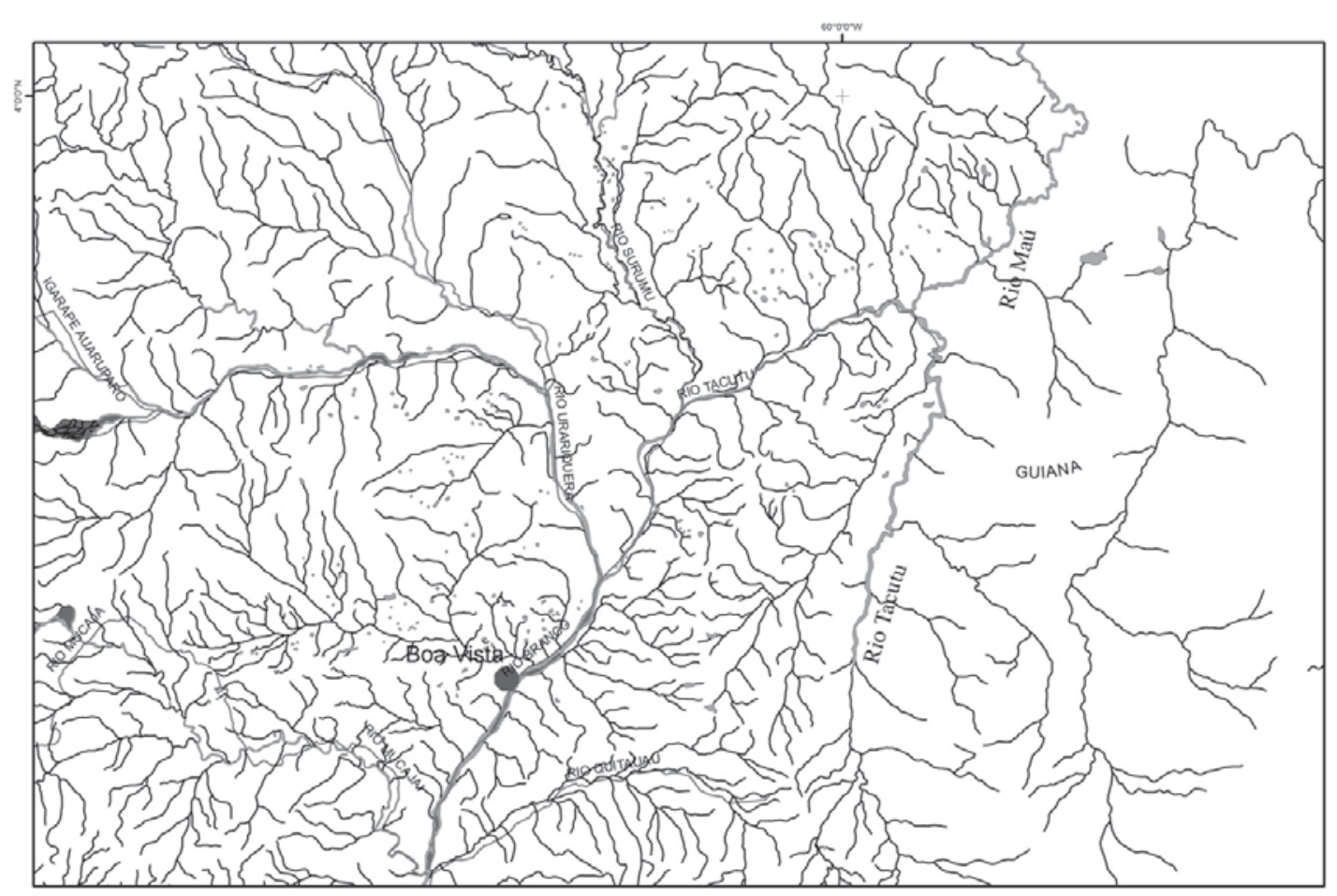

Figura 2 - Arranjo e orientação da rede de drenagem do setor nordesde de Roraima.

A análise da rede de drenagem relevou 4 (quatro) padrões de drenagem obedecendo a classificação proposta por Howard (1967): treliça modificado, retangular, subdendrítico e dendrítico.

O padrão treliça modificado domina grande parte do hemigráben sendo característico de áreas encontradas em estruturas sedimentares como a serra do Tucano.

No que se refere ao padrão retangular, percebe-se o aspecto ortogonal característico desse padrão, consequência da influência exercida por falhas e pelo sistema de juntas. 


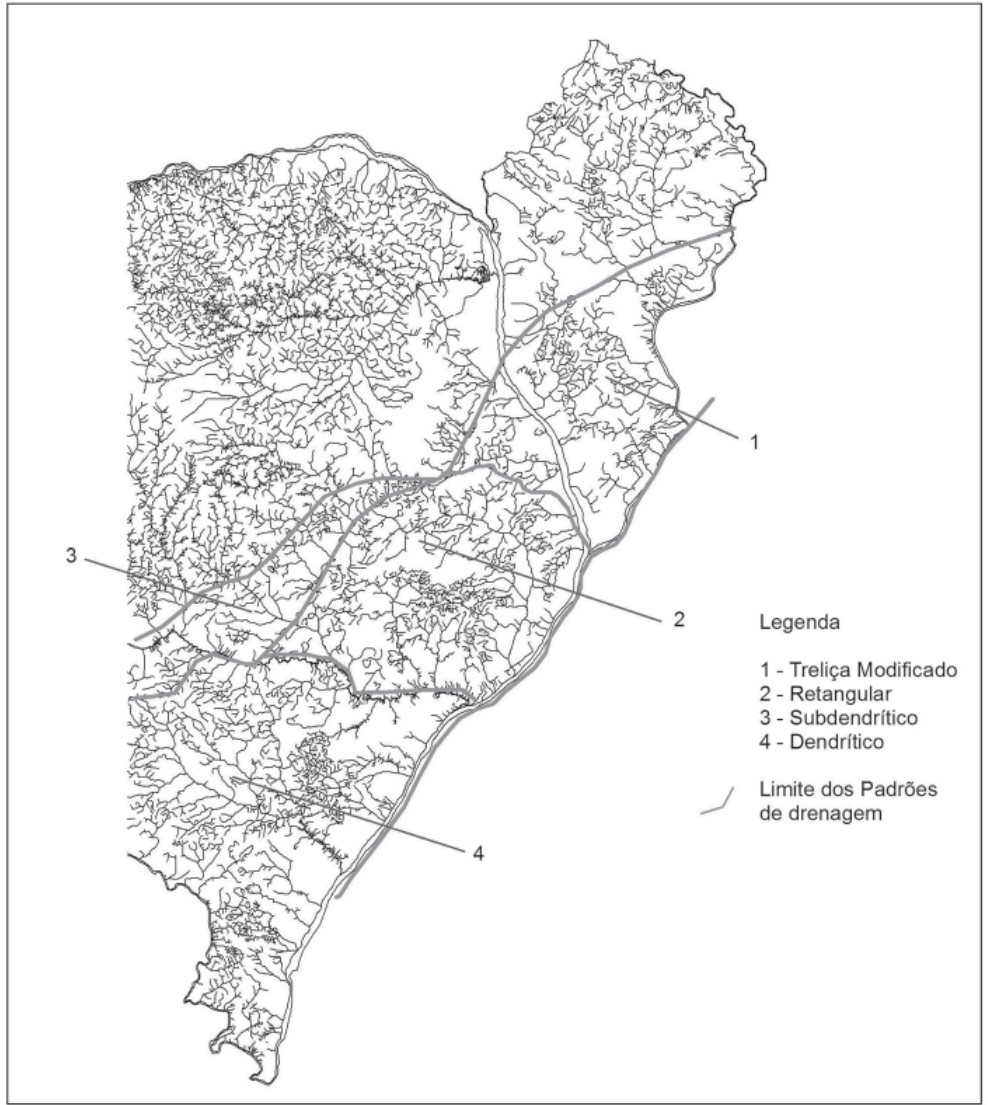

Figura 3 - Padrões de drenagens identificados na calha do hemigráben.

Costa (2006), descreve que tal orientação exerce um importante papel, sendo uma das características que mais identificam os domínios do hemigráben do Tacutu: a forte orientação da rede de drenagem, em duas principais direções, uma relacionada ao eixo longitudinal do Gráben do Tacutu (NE - SW), identificada principalmente nas drenagens de primeira ordem pelo alinhamento do Rio Murupu, que, associados ao conjunto de serras e morros (serras Murupu e Flechal e Morro Urubu), delineiam a ombreira noroeste do gráben, enquanto a segunda direção relacionada a pequenos morros alinhados na direção NW - SE limita a ombreira da estrutura no setor sudeste.

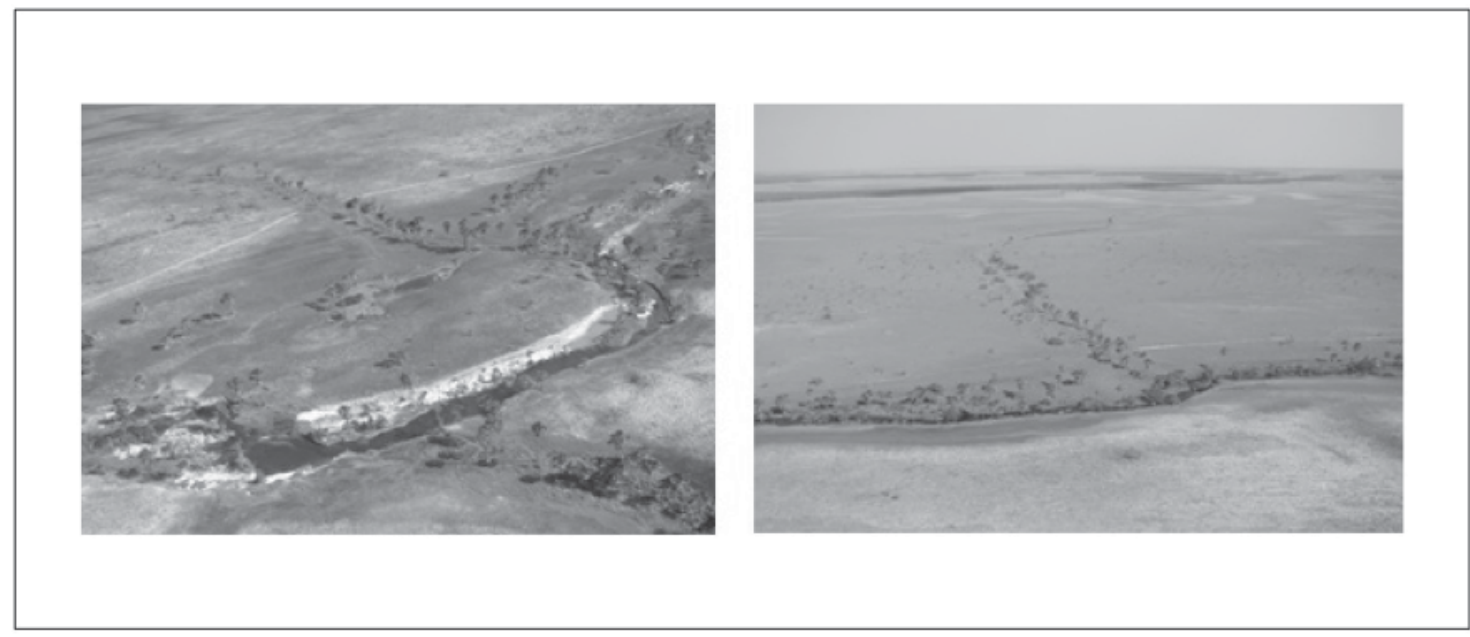

Figura 4 - Drenagens controladas por falhas, influenciadas pelo controle estrutural do hemigráben, notam-se padrões do tipo retangular a sub-retangular. Região do rio Murupu. 
Os padrões dendrítico e subdendritíco estão relacionados principalmente às áreas abaciadas recobertas por areias hidromórficas distribuídas amplamente ao longo da estrutura, à exceção dos relevos elevados.

Em relação aos campos de paleodunas há uma carência de estudos mais específicos. Entretanto, por correlação com os campos de dunas do rio Catrimanià sudoeste da área de estudo, Santos (1994) descreve essas ocorrências como areias brancas elaboradas em algum estágio do Pleistoceno superior, ou até mesmo Holoceno a partir do retrabalhamento de áreas arenosas rio acima em um clima semi-árido.

Na terceira etapa foi construído o modelo digital do terreno (MDT) através dos aplicativos do ArcGis 9.3 utilizando-se das imagens raster da missão da Nasashuttle radar topographymission(SRTM) por meio do aplicativo 3D Analyst(ArcGis) e aplicando técnicas de declividade, sombreamento e paleta de cores obteve-se um dos MDTs.

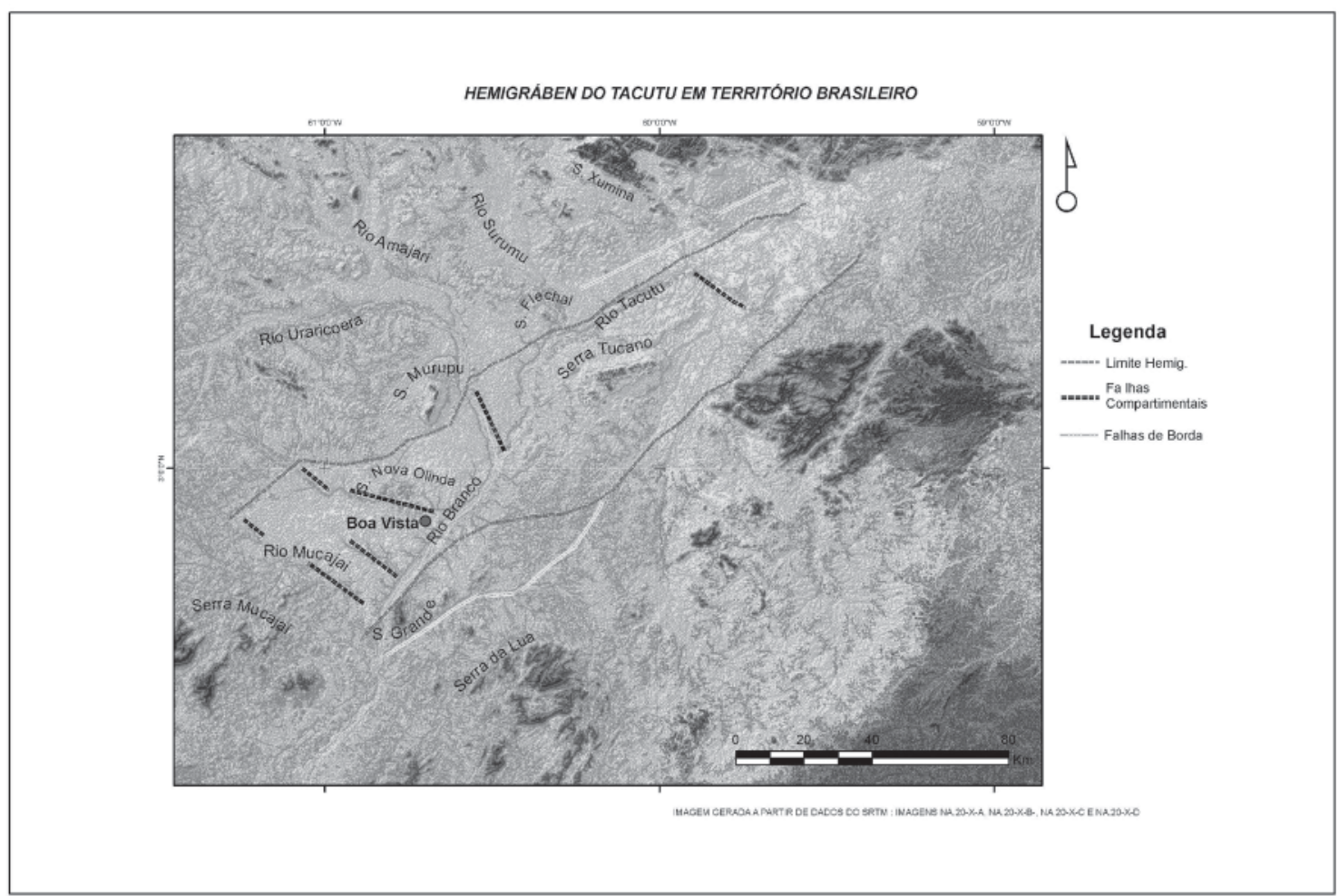

Figura 5 - MDT oriundo de imagenraster da missão da Nasa - shuttle radar topographymission (SRTM) aplicando técnicas de declividade, sombreamento, paleta de cores e transparência.

Outro foi obtido através da interpolação com equidistância de curvas de 100m e através de redes triangulares irregulares (TIN - Triangular Irregular Network). A malha triangular irregular ou TIN é uma estrutura que representa uma superfície através de um conjunto de faces triangulares interligadas, preferiu-se utilizar exagero vertical zero (0), assim, o resultado se deu de forma satisfatória, no qual a declividade do relevo tornou-se mais aproximada do real, permitindo uma interpretação de melhor qualidade.

Os modelos digitais do terreno foram sobrepostos as cartas planialtimétricas bem como com a imagens de satélites georreferenciadas, por meio da técnica de transparência proporcionando uma melhor interpretação das estruturas observadas em campo, principalmente aquelas relacionadas aos alinhamentos de relevo e anomalias de drenagens.
As etapas de campo foram intercaladas com a realização das demais atividades, no qual foram observados os afloramentos, as unidades litológicas, com atenção as rochas que formam o embasamento cristalino, o processo de laterização e a observação dos sedimentos que recobrem o hemigráben, com a utilização da bússola foram realizadas 104 amostragens de campo obtendo medidas das descontinuidades (falhas, juntas e fraturas)

\section{Resultados e Discussões}

Os trabalhos de campo, a modelagem digital de terreno, aliados aos dados da literatura,em especial aos mapas geomorfológicos propostos por Franco et al. (1975), IBGE (2005) em escala1.1.000.000 e ainda em 
trabalhos realizados por Costa, Falcão e Sousa (2007), permitiram individualizar o hemigráben em 03 compartimentos denominados informalmente pela carência de estudos na área e pelo detalhe do trabalho específico ao hemigráben, objeto da investigação, com características específicas: o $1^{\circ}$ compartimento representa as Planícies Aluviais, que constituem cerca de $75 \%$ da área mapeada, o $2^{\circ}$ constituia Depressão Boa Vista, representando cerca de $20 \%$ e o $3^{\circ}$ caracteriza os Planaltos Residuais, que corresponde a cerca de $5 \%$ do hemigráben, que por sua vez foramindividualizados conforme suas características geológicas-geomorfológicas em: ResiduaisVulcânicos (Domínio Vulcânico Apoteri), Residuais Sedimentares (Serra do Tucano) e Residuais do Proterozóico.

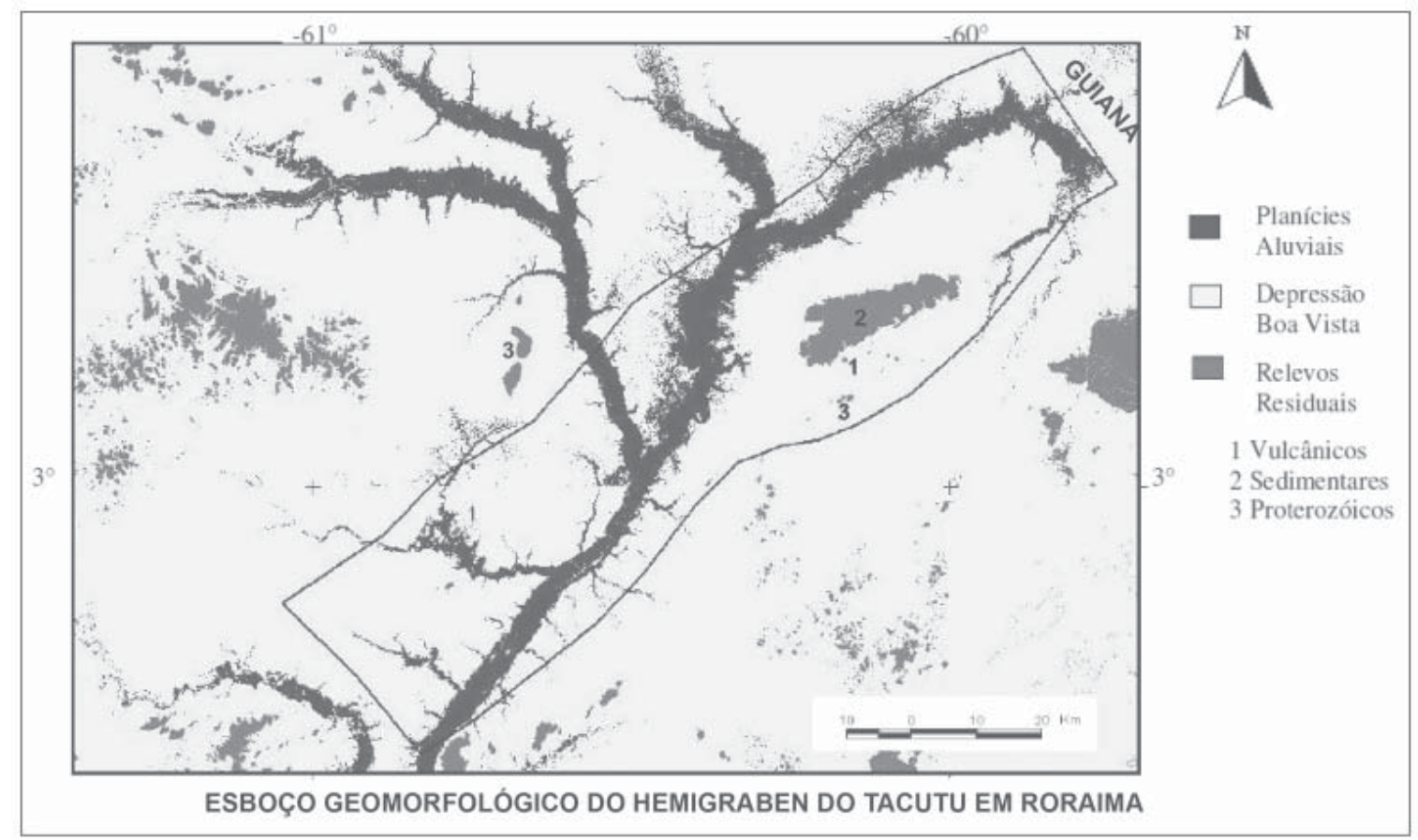

Figura 6 - Mapa da Compartimentação Geomorfológica do Hemigráben Tacutu, adaptado de Brasil (1975), IBGE (2005) e, Costa et al. (2007).

\section{Compartimento 01: Planícies Aluviais}

Esse compartimento caracteriza-se por ser uma região plana a levemente plana, correspondendo a uma extensa área de agradação estendendo na forma de faixas alongadas, constituídas por sedimentos sub-recentes representados por areias, argilas e seixos semi-consolidados, em geral associados aos depósitos holocênicos de origem fluvial, sujeita a inundações periódicas. As Planícies Aluviais distribuem-se através de trechos contínuos, por vezes assimétricos, sobre vários ambientes geológicos, porém, sendo mais bem representada nas porções dos rios instaladas nas superfícies aplainadas sobre as rochas sedimentares da bacia Mesozóica.

\section{Compartimento 02: Depressão Boa Vista}

A Depressão Boa Vista é representada por uma superfície de aplainamento desenvolvida sobre rochas précambrianas e fanerozóicas, sobre a qual estão instalados delgados depósitos de areias inconsolidadas com elevado grau de selecionamento e livre de impurezas. Caracteriza-se, na realidade, por representar um estágio final de evolução de uma paisagem, submetida predominantemente por um recuo paralelo das vertentes, encontrando-se emseu interior elevações residuais de vertentes íngremes. Os sedimentos encontrados no interior do hemigráben são provenientes das suas bordas que, devido aos ciclos de erosão e deposição que resultaram em preenchimento, se acumularam, fornecendo material para a sedimentação recente, denominada anteriormente de Formação Boa Vista, mais recentemente entendidos como unidade Areias Brancas conforme Melo et al. (1978).

Essas superfícies aplainadas se caracterizam por apresentar um relevo suave, representando as cotas regionais que variam desde 87 metros, nas drenagens mais expressivas, a140 metros próximo às grandes elevações, sendo possível notar, ao longo da BR 401, os degraus de elevações suaves, cujas as altitudes oscilam entre 80 a 100 metros. 

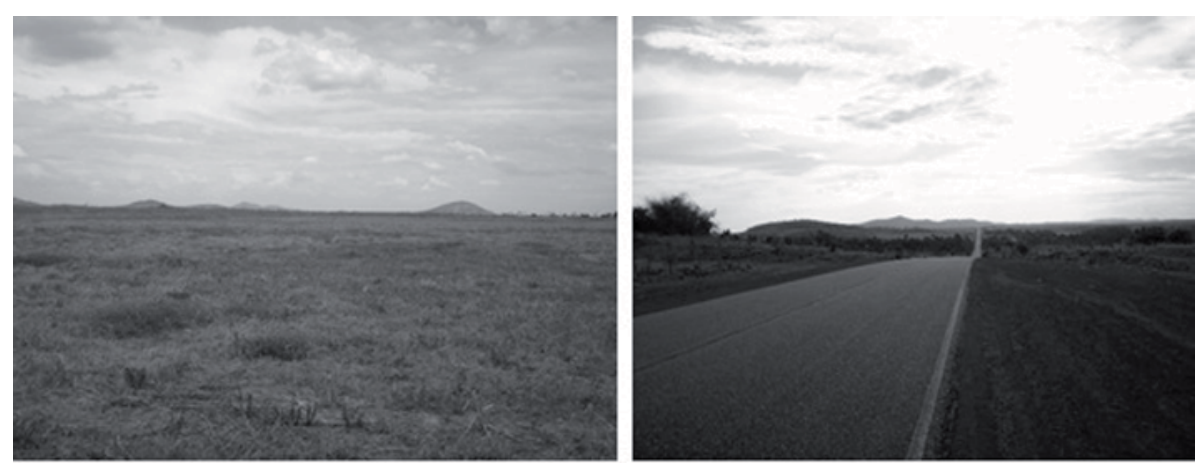

Figura 7 - Depressão Boa Vista nos domínios do Hemigráben do Tacutu, BR 40. Nota-se a presença de degraus que variam entre 80 a100m de altitude.

\section{Compartimento 03: Planaltos Residuais}

\section{a) Planaltos Residuais Vulcânicos}

Esse compartimento é caracterizado pela presença de rochas vulcânicas que se elevam interrompendo localmente a extensa região plana. Fazem parte desse alto estrutural: o conjunto de morros da serra Nova Olinda, morro do Redondo e serra Pau Rainha, correspondendo em parte ao Complexo Vulcânico Apoteri (CPRM, 1999).

A maior expressão desse compartimento está representada pelo conjunto de morros Nova Olinda, que situa-se nas adjacências da sede municipal, caracterizando pela presença de derrames vulcânicos, delineando morros isolados alinhados, na realidade, um relevo residual de idade Juru - Cretácea, correspondendo à parte sudoeste do hemigráben.
O morro do Redondo, comparece nas adjacências da Formação Tucano, sendo este um afloramento de basaltos, que se destaca ao longo da BR- 401, sentido Boa Vista Bonfim, o qual representa um residual que corresponde a unidade basal do hemigráben.

Uma ocorrência isolada no interflúvio do Igarapé Água Boa - Rio Mucajaí, na região da Fazenda Pau Rainha é o marco que delimita uma das últimas ocorrências dessa unidade, localiza-se a cerca de $20 \mathrm{~km}$ ao sul da área urbana de Boa Vista (BRASIL, 1975; COSTA, 2006).

Essas áreas constituem remanescentes residuais que se destacam na planura da Formação Boa Vista, se caracterizam como morros que gradam para uma superfície suavemente ondulada(colinosa) em direção a base do relevo.
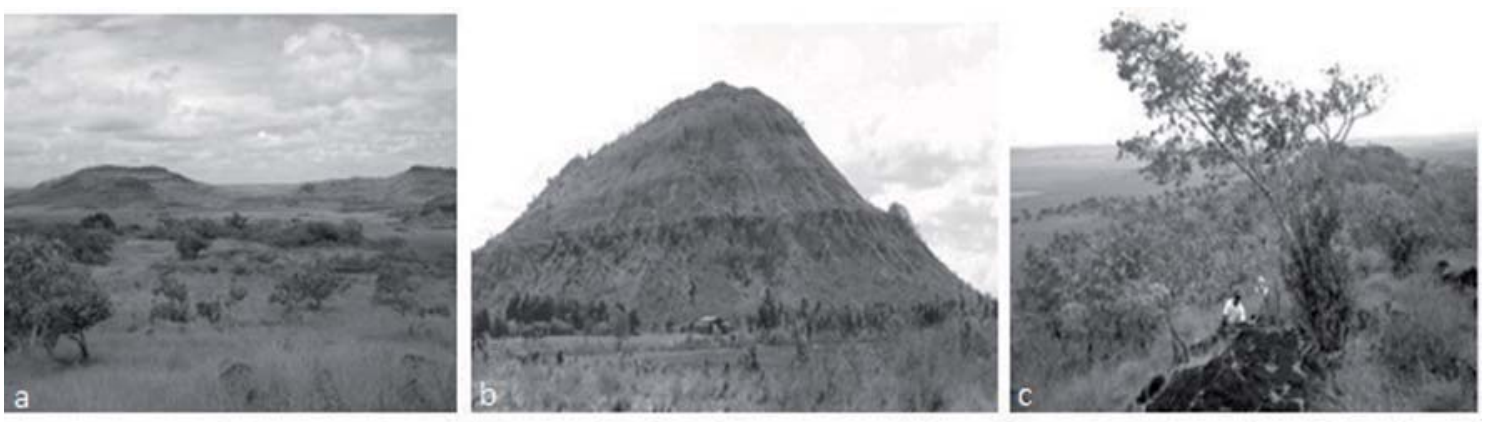

Figura 8 - Relevos residuais vulcânicos, a): Conjunto de Serra Nova Olinda em Boa Vista; b) Morro do Redondo, município de Bonfim e c) Serra Pau Rainha no município de Boa Vista.

b) Planalto Residual Sedimentar Serra do Tucano

A Serra do Tucano, localizada ao longo da BR - 401, constitui-se em uma área elevada, elaborada em rochas Jurocretáceas, tendo como ponto mais alto o morro da Antena, com cerca de 320 metros, predomina um conjunto de serras e morros interligados, notando-se ainda a presença de inúmeros vales com estrutura abrupta em forma de "V", encaixado em áreas de falhamentos.

Nas bordas dessa elevação comparece um relevo colinoso que se mostra levemente ondulado, caracterizado por colinas pequenas e médias, de vertentes côncavas e convexas de baixa declividade, com alguns vales abertos e fechados ou amplamente ravinados.

A presença dos vales na Serra do Tucano denotam uma característica de área soerguida, um relevo jovem que se apresenta anômalo na planície do hemigráben. A presença de família de falhas e juntas na Serra do Tucano, em concordância com Brasil (1975),CPRM (1999) e Costa (1996) são interpretadas como falhas transcorrentes e estão orientadas, preferencialmente na direção NE - SW, em geral, no sentido 225/65. 


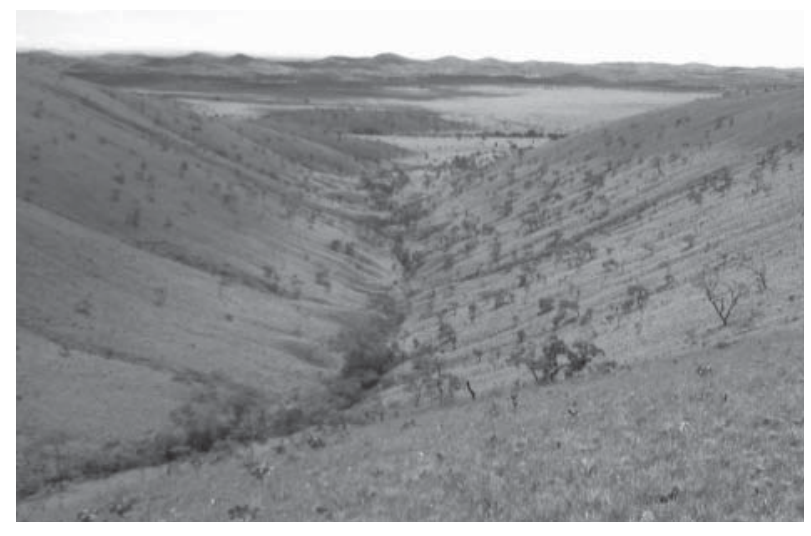

Figura 9 - Serra do Tucano, com a presença de vales encaixados e drenagem controlada, BR - 401, sentido Boa Vista - Bonfim, em meio a sedimentos da Formação Boa Vista.

Nessa região, as evidências sísmicas relatadas por Eiras e Kinoshita (1988) indicam uma área sinclinal dobrada,evento esse que teria ocorrido após a deposição do arenito Tucano. Na Serra do Tucano destacam-se também pavimentos e blocos de cangalaterítica com notável contribuição de seixos de quartzo leitoso, angulosos asubarredondados que chegam a alcançar espessura em torno de 10 metros.

\section{c) Planaltos Residuais Proterozóicos}

Esse compartimento é caracterizado pela presença de relevos residuais que pertencem ao Grupo Cauarane, representados pelos morros Truaru e Urubu.

Essa sequência de morros alinhados na direção NE SW, também é bem visualizada nas proximidades do Morro do Redondo (BR-401), borda sudoeste do hemigráben, correspondendo a residuais do Grupo Cauarane, neste local representados por quartzitos e meta-cherts. Esses remanescentes demonstram a evolução do relevo regional provavelmente desde a instalação da bacia, seguida de sua inversão, e a dissecação dessas ombreiras ao longo dos tempos cenozoicos.

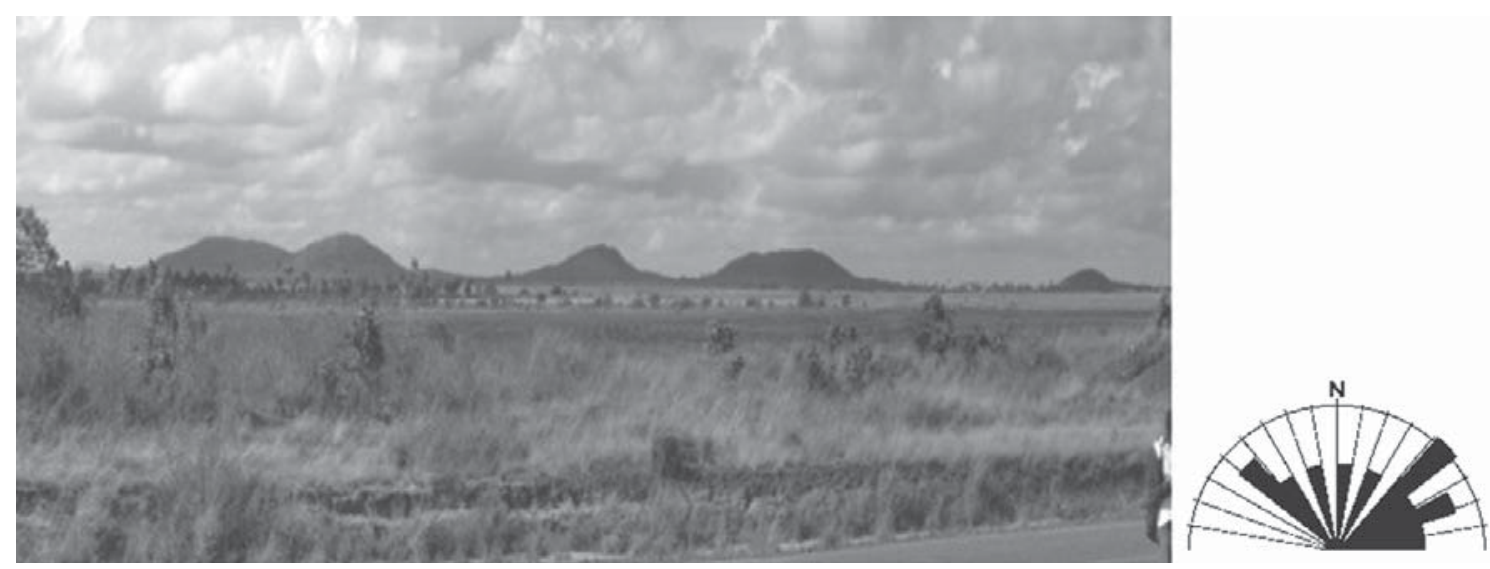

Figura 10 - Sequência de morros orientados na direção nordeste limitando a borda sudeste do hemigráben.

No morro Truaru, sentido NE, percebe-se a presença de vários morros alinhados, que num contexto geral, representam o limite noroeste do hemigráben. Quando o Rio Uraricoera encontra o hemigráben ele sofre um desvio, fato que pode estar relacionado a duas situações: ou devido a um prisma rotacionário, onde o rio ao entrar nessa estrutura, foi capturado pelo rio Branco, ou devido a uma falha compartimental ortogonal a estruturação do hemigráben. A presença de morros internos à bacia evoca a interpretação de prismas rotacionados durante a inversão fraca do hemigráben, em outras situações, os morros indicam as ombreiras da própria bacia, a exemplo do Morro Urubu e conjunto de colinas associadas ao morro do Barro.

As evidencias das ocorrências paleoclimáticas estão relacionadas as abundantes linhas de pedras sobrepostas por um espesso manto de latossolo amarelo e vermelho na faixa de até 4 metros de espessura, pelos campos de matacões late- ríticos isolados possivelmente representando remanescentes de crosta laterítica e pelos campos de dunas (areias brancas) da Depressão Boa Vista.

\section{Conclusões}

O hemigráben do Tacutu revela uma geomorfologia caracterizada por um extenso aplainamento, com relevo suave e dissecação localizada, representada por alguns campos arenosos com feições de paleodunas. Alguns testemunhos vulcânicos e terrenos lateríticos em meio a esse processo sedimentar revelam um embasamento irregular, controlado ainda por uma tectônica recente, em alguns casos remanescentes erosionais das atuais drenagens que por ali se instalaram.

Foi possível individualizar a evolução do relevo em três compartimentos principais: compartimento 1 (Planície Aluvial) evidenciada por ser uma área plana suave ondulada, 
estendendo-se por faixas alongadas elaboradas por drenagens preexistentes, onde foram depositados sedimentos arenosos, argilosos e conglomeráticos semi-consolidados, em geral associados aos depósitos do Quaternário; compartimento 2 (Depressão Boa Vista) representada por uma superfície de aplainamento, esta desenvolvida sobre rochas pré-cambrianas e fanerozóicas; e compartimento 3 (Planaltos Residuais) individualizados em: Residuais de idade mesozóica(Vulcânicos) representados pelo Domínio Apoteri, Residuais Sedimentares, representado pela Serra do Tucano e os Residuais do Proterozóico, remanescentes que demonstram a evolução do relevo regional provavelmente desde a instalação da bacia, seguida de sua inversão e a dissecação desses residuais ao longo dos tempos cenozóicos.

O processo evolutivo dessa bacia sedimentar esteve condicionado a sucessivas oscilações climáticas ocorridas na região durante o final do Terciário e todo Quaternário, cujo registro geológico é representado por abundantes linhas de pedras no relevo colinoso e campo de paleodunas na extensa região plana.

A evolução do relevo tem ainda a contribuição de atividade neotectônica evidenciada pela presença de inúmeros falhamentos normais que registram reativações como falhas transcorrentes e compartimentais que delineiam várias anomalias de drenagens e que delimitam lateralmente o hemigráben e internamente geram regiões abatidas e soerguidas, respectivamente.

\section{Agradecimentos}

Ao CNPq pelo apoio financeiro (proc.nº 476735/2006-8) e ao programa PRONAT/UFRR.

\section{Referências Bibliográficas}

FRANCO, E.M.S.; DEL'ARCO, J.O.; RIVETTI, M. Geomorfologia. In: BRASIL.Projeto Radambrasil. Levantamento dos Recursos Naturais. Folha NA 20Boa Vista e parte das Folhas NA 21 Tumucumaque, NB 20 Roraima e NB 21. IBGE, Rio de Janeiro, 2003. CD-ROM.
COSTA, J. B. S; IGREJA, H.L.S.; BORGES, M.S.; HASUI, Y. O quadro tectônico regional do mesozóico na região norte do Brasil. In: SIMPÓSIO DE GEOLOGIA DA AMAZÔNIA, 3, Belém. Anais... Belém, 1991. p. 166-192.

COSTA, J.B.S.; COSTA, J. A. V.O quadro neotectônico da região nordeste do Estado de Roraima. In: SIMPÓSIO DE GEOLOGIA DA AMAZÔNIA, 5. Belém - PA. Anais... 1996. p.284-286.

COSTA, J.A.V. Relatório Técnico de Geologia e Geomorfologia: subsídio ao Plano Diretor do município de Boa Vista. Rio de Janeiro: IBAM. Disponível em:http://www.boavista.rr.gov.br/produtos/ produto7/03_DiagInt_Geologia.PDF\#search=\%22graben\%20 do\%20tacutu\%22> Acesso em: 05 nov. 2006.

COSTA, J.A.V.; FALCÃO, M.T.; SOUZA, V.Expressão geomorfológica das ombreiras do Hemigráben do Tacutu no estado de Roraima. In: Simpósio de Geologia da Amazônia, 10, Porto Velho. Anais... Porto Velho, SBG,2007, p. 364-367.

CPRM. (1999). Programa Levantamentos Geológicos Básicos do Brasil. Projeto Roraima Central, Folhas NA.20-X-B e NA.20-X-D (inteiras), NA.20-X-A, NA.20-X-C, NA.21-V-A e NA.21-V-C (parciais). Escala 1:500.000. Estado do Amazonas. Brasília: CPRM, CD-ROM

LIMA, M. I. C. de; OLIVEIRA, E. P., TASSINARI, C.C.G. .Cinturões Granulíticos da porção setentrional do Cráton Amazônico. In: SIMPÓSIO DE GEOLOGIA DAAMAZÔNIA, 1., 1982, Belém. Anais... Belém : SBG, v. 1, 1982, p.147-162.

MELO, AF.F.; SANTOS, A.J.; CUNHA, M.T.P.; CAMPOS, M.J.F.; D’ANTONA, R.J.G. DAMIÃO, R.N. Projeto Molibdênio em Roraima. Rel. Final. 6v.Manaus. 1978.

PINHEIRO, S. S.; NUNES, A. C. B.; COSTI, H. T.; YAMAGUTI, H. S.; FARACO, M. T. L.;REIS, N. J.; MENEZES, R. G.; RIKERS. R. L.; WILDNER, W.(1981)Projeto CatrimâniUraricoera: Relatório de Progresso. Manaus: DNPM/CPRM. v.II-B: p. 399- 401.

RICCOMINI, C.; CRÓSTA, A.P. Análise preliminar de lineamentos em imagens de sensores remotos aplicados a prospecção mineral na área dos granitóides Mandira, SP. Bol. IGUSP,Série Científica.1988.

SANTOS, J. O. S. (1992). O Pantanal Setentrional e os Campos de Dunas da Amazônia Ocidental. Simpósio Internacional do Quaternário da Amazônia, resumos (Unesco: FUA/QUA). 